Eur. J. Clin. Chem. Clin. Biochem.

Vol. 31, 1993, pp. 191-195

(C) 1993 Walter de Gruyter \& Co. Berlin - New York

\title{
Neopterin and Human Immunodeficiency Virus Infection
}

\section{By B. Hofmann}

Hvidovre Hospital, Municipality of Copenhagen University, Department of Infectious Diseases, Copenhagen, Denmark

(Received October 10, 1992/January 4, 1993)

Summary: Neopterin concentrations increase in serum and urine within the first week of infection with HIV and remain increased throughout the infection. In particular, changes in neopterin concentration precede decreases in CD4 $\mathrm{T}$ cell numbers and the development of clinical disease, and they can be used to predict the later development of AIDS. The increased neopterin concentrations show that the immune system is activated in HIV infection and demonstrate the presence of an interaction between the virus and the immune system. The most important future use of neopterin measurements may be in fast evaluation of new drugs in HIV infection.

\section{Introduction and Background}

The average of ten years between infection and development of AIDS distinguishes infection with HIV from most other infections. Many HIV-induced changes, however, can be detected in the immune system during these ten years of latent infection. Certain immune changes correlate with the time for the later development of AIDS, and are therefore related to the underlying pathological process of the disease. Many of the changes are established immediately after HIV seroconversion and remained detectable throughout the disease. The serum concentration of neopterin is such an immünological quantity. Neopterin is a marker for infectious diseases, especially viral diseases involving the macrophage system.

\section{Production of neopterin}

Neopterin is produced in response to immune activation. Many medical conditions in which immune activation is a part of the disease have high serum concentrations of neopterin. Such conditions are allogeneic graft rejections, autoimmune diseases, infectious diseases, and after immunostimulatory treat- ment with interferon gamma or interleukin-2 (1). Extensive work has shown that macrophages are the primary neopterin-producing cells, which release neopterin in response to interferon gamma $(2,3)$. Under different in vitro conditions, B cells also release neopterin in response to either interferon gamma or interleukin- 2 by an unknown mechanism $(4,5)$. Neopterin can be measured in either serum or in urine and the two measurements correlate well (6). Measurements of neopterin in urine are particularly useful when frequent measurements are required in infants. Neopterin is quantitated by two different methods. One is a radioimmune assay using radioactively labelled neopterin and a monoclonal antibody against. neopterin (7). The other is high performance liquid chromatography separation and quantitation by comparison with samples containing known amounts of neopterin (8). Both methods have pitfalls, especially in the collection and storage of samples. Although neopterin is rather stable, light, high temperatures or repeated thawing and freezing may interfere with quantitation. For urine samples, the most reliable results are obtained when neopterin is measured in spontaneous early urine and related to the simultaneously measured urine creatinine concentration. 


\section{Immune activation in HIV infection}

Late in the course of infection with HIV, paralysis of the cellular immune function $(9,10)$ as well as impairment of the ability to replenish the CD4 $\mathrm{T}$ cells lead to development of AIDS. The impairment of immune function, however, seems to go hand in hand with the general immune activation. Wachter, Fuchs and colleagues showed as early as 1983 that serum concentrations of neopterin were strongly increased in patients with $\operatorname{AIDS}(11,12)$. With the knowledge available then it was very difficult to imagine how immune activation and deficiency could occur simultaneously. To day, it is well known that immune activation can lead to either an immune response or anergy (13), and the two concepts are no longer contradictory. In retrospect, before HIV was discovered, many researchers believed that AIDS was due to a generalized immune activation resulting in an exhaustion of the immune system. This concept was based on the finding of increased concentrations of CD8 $T$ cells in the peripheral blood (14) and the polyclonal activation of $\mathrm{B}$ cells resulting in increased concentrations of immunoglobulin (15).

Unfortunately, for several years the focus was shifted totally toward the newly discovered HIV virus. In 1989, an article by Fahey et al. again draw the attention toward immune activation in HIV infection (16). By testing samples from the large multicenter AIDS cohort study (MACS) in Los Angeles and applying survival statistics, the article showed that the concentrations of various serum activation markers, alone or in combination, were highly predictive for the development AIDS in HIV-seropositive subjects. Other articles showed that neopterin concentrations in serum measured at an average time of three months after HIV seroconversion also were predictive for the decline in CD4 $\mathrm{T}$ cell numbers after four and five years infection (17). Although the latter study showed that neopterin serum concentrations have the strongest predictive power, other serum activation markers such as $\beta_{2}$-microglobulin, soluble interleukin-2 receptors and soluble $C D 8$ have been shown to have similar properties $(18-20)$. In most risk groups, a strong correlation between neopterin and $\beta_{2}$-microglobulin concentrations in serum indicates that the pathological mechanism responsible for the increase in these markers is the same. In contrast, soluble interleukin-2 receptor concentrations do not correlate with neopterin concentrations and, therefore, seem to be driven by a separate mechanism. Neopterin concentrations also correlate with phenotypic cellular activation markers such as HLA-DR, CD8/38 and CD8/ CD45RA (21).
Mechanism behind the neopterin production in HIV infection

The mechanism by which HIV infection induces immune activation is unknown, although we have earlier shown that HIV proteins are able to induce neopterin production in normal peripheral blood mononuclear cells in vitro (unpublished, Hofmann, Nishanian, Fahey). The neopterin production both in vitro and in vivo is most likely secondary to induction of interferon gamma production. Increased serum concentrations of interferon gamma have been found in HIVseropositive subjects (22) and could as such explain the neopterin production by inducing activation of macrophages and perhaps $B$ cells. That macrophages are activated in HIV infection has been demonstrated by showing increased serum concentrations of macrophage-derived interleukin-6 (23). Other evidence for a relationship between neopterin production and the viral infection is that serum neopterin concentrations correlate with the in vitro replicative capacity of HIV-1 isolates (24). The relationship to the cellular immune deficiency is indicated by the relationship between neopterin concentrations and the decreased in vitro ability of $\mathrm{T}$ cells from HIV-seropositive subjects to produce interleukin-2 (25).

\section{Neopterin Concentrations in Different Stages of HIV Infection}

\section{HIV seroconversion and symptomatic primary infection}

Serum neopterin concentrations increase early after infection with HIV. Gaines et al. (26) showed highly increased neopterin serum concentrations in $4 / 4$ individuals tested within the first few days of primary HIV infection. These data are similar to those obtained in rhesus macaques after experimental infection with SIV showing increased neopterin concentrations within the first two weeks of infection (27). Similar findings are likely in non-symptomatic individuals, since Melmed et al. (17) showed an increased neopterin concentration in 29/29 individuals tested at an average time of three months after HIV seroconversion. The increase in neopterin concentration is not specific for HIV but is an early marker for an ongoing viral infection.

\section{Asymptomatic disease}

The highest average serum neopterin concentrations are found about one year after HIV seroconversion, whereafter the concentration dicreases to an average concentration that remains about twice the pre-sero- 
conversion concentration (17). This concentration, however, varies from individual to individual. Thus, those with the fastest decline in CD4 $\mathrm{T}$ cell numbers have the highest neopterin concentrations, whereas those with stable CD4 T cell numbers have the lowest concentrations (17).

\section{HIV-related symptoms and AIDS}

Cross sectional studies of HIV-seropositive subjects showed progressively increasing mean concentrations of neopterin in the order: asymptomatic HIV seropositive individuals < patients with AIDS-related symptoms but with AIDS (ARC) < AIDS patients with the highest neopterin concentrations $(28,29)$.

\section{Neopterin as a prognostic marker for development of AIDS}

The clinical relevance of neopterin concentrations is the power to predict later development of AIDS and death. Several studies have shown that high concentrations of serum neopterin correlate with early AIDS development, whereas low concentrations are associated with a disease-free interval of several years (16, $17,29-32)$. Neopterin concentrations provide prognostic information in most studies almost or as strong as the CD4 T cell numbers. Since neopterin concentrations and CD4 $\mathrm{T}$ cell numbers do not strongly correlate, neopterin concentrations provide prognostic information in addition to CD4 $\mathrm{T}$ cell numbers, and the two quantities together give a stronger prediction of the time for development of AIDS than either one of them alone $(16,30-33)$.

\section{Neopterin in different risk groups of HIV-infected individuals}

Although the association between increased neopterin and HIV infection was first established in homosexual men other risk groups have also been extensively studied, such as haemophiliacs $(34-36)$, i.v. drug users $(33,37)$ and Africans $(38,39)$. Other infections than HIV can also lead to increased neopterin concentrations, which can complicate the interpretation in, for example, patients from Africa (40). In i.v. drug users, only hepatitis, and not the frequent bacterial infections, leads to increased neopterin concentrations (41). The bacterial infections, however, may interfere with other activation markers, since the $\beta_{2}$-microglobulin concentrations, which usually are strongly correlated with neopterin concentrations, do not have prognostic value in i. v. drug users (33).
Neopterin concentrations have a special implication in HIV-infected infants, because the physiologically high CD4 $\mathrm{T}$ cell numbers in infants reduce the usefulness of this quantity. Although maternal neopterin concentrations do not predict maternal transmission (42), neopterin concentrations are increased in HIVinfected infants. When other infections are excluded, high neopterin concentrations in infants and older children correlate with disease severity and are predictive of disease progression (43-45).

Neopterin as a marker in neurological HIV disease

Neopterin concentrations do not distinguish between different clinical manifestations of HIV-induced diseases. In neurological HIV disease, however, direct measurements of neopterin in cerebrospinal fluid have been shown to correlate with the degree of neurological involvement $(46-47)$. The concentrations of neopterin in cerebrospinal fluid in individuals with neurological HIV disease are increased above the serum and urine concentrations (46).

Neopterin as a marker for the effect of antiviral treatment in HIV infection

Because of the prolonged course of the disease, survival analysis is not of great value in the evaluation of the effect of new antiviral treatments. The effect of the treatment on paraclinical quantities associated with the disease pathology (such as neopterin, $\beta_{2-}$ microglobulin and CD4 T cell numbers) has, therefore, been evaluated. While the increase in CD4 T cell numbers is small in response to treatment with zidovudine, this drug decreases the immune activation, as indicated by the decrease in neopterin, which can be detected within the first week of treatment (49). Also, the $\beta_{2}$-microglobulin concentration decreases, but the two markers respond differently, neopterin concentrations remaining below baseline during treatment, while $\beta_{2}$-microglobulin concentrations return to normal within half a year $(50,51)$. The significance of this is unknown.

\section{Conclusions}

The strong correlation between neopterin concentrations and HIV disease progression/activity has established neopterin as an important marker of the disease pathology. Further, neopterin meaurements have directed attention away from the viral infection alone and back to the interaction between the immune sys- 
tem and the virus. The ability to measure neopterin in urine makes it an easily accessible marker. In future, neopterin may have particular importance in evaluating new drugs for the treatment of HIV infections.

\section{Acknowledgement}

I would like to acknowledge Dr. J. L. Fahey at University of California, Los Angeles. Most of my work referred to in this paper was done while working in Dr. J. L. Fahey's group.

\section{References}

1. Fuchs, D., Hausen, A., Reibnegger, G., Werner, E. R., Dietrich, M. P. \& Wachter, H. (1988) Neopterin as a marker for activated cell-mediated immunity: application in HIV infection. Immunol. Today 9, 150-155.

2. Huber, C., Batchelor, J. R., Fuchs, D., Hausen, A., Lang, A., Niederwieser, D., Reibnegger, G., Swetly, P., Troppmair, J. \& Wachter, H. (1984) Immune response-associated production of neopterin - Release from macrophages primarily under control of interferon-gamma. J. Exp. Med. $160,310-316$.

3. Bitterlich, G., Szabo, G., Werner, E. R., Larcher, C., Fuchs, D., Hausen, A., Reibnegger, G., Schulz, T. F., Troppmair, J., Wachter, H. \& Dierich, M. P. (1988) Induction of mononuclear phàgocytes to produce neopterin. Immunobiol. 176, $228-235$.

4. Hofmann, B., Bass, H., Nishanian, P., Faisal, M. \& Fahey, J. L. (1992) Production of neopterin, beta-2 microglobulin, and soluble IL-2 receptor reflect different lymphoid populations and cytokines: Immune activation in vitro and in vivo. Clin. Exp. Immunol. 88, 548-554.

5. Barak, M., Merzbach, D. \& Gruener, N. (1990) Interleukin1- and neopterin-induced release from peripheral blood mononuclear cells. Scand. J. Clin. Lab. Invest. 50, 705714.

6. Denz, H., Fuchs, D., Huber, H., Nachbaur, D., Reibnegger, G., Thaler, J., Werner, E. R. \& Wachter, H. (1990) Correlation between neopterin, interferon-gamma and haemoglobin in patients with haematological disorders. Eur. J. Haematol. 44, 186-189.

7. Rokos, H. \& Rokos, K. (1983) Pteridine determinations. In: Chemistry and Biology of Pteridines (Blair, J. A., ed.) pp. 815-819, de Gruyter, Berlin.

8. Werner, E. R., Fuchs, D., Hausen, A., Reibnegger, G. \& Wachter, H. (1987) Simultaneous determination of neopterin and creatinine in serum with solid phase extraction and on-line elution liquid chromatography. Clin. Chem. 33, 2028-2033.

9. Hofmann, B., Lindhardt, B. O., Gestoft, J., Petersen, C. S., Platz, P., Ryder, L. P., Odum, N., Dickmeiss, E., Nielsen, P. B., Ullman, S. \& Svejgaard, A. (1987) The lymphocyte transformation response to pokeweed mitogen is a highly predictive parameter for the development of AIDS and AIDS-related symptomes in homosexual men with HIV antibodies. Br. Med. J. 295, 293-296.

10. Hofmann, B., Jakobsen, K., Odum, N., Dickmeiss, E., Platz, P., Ryder, L., Petersen, C., Mathisen, L., Bygbjerg, I., Faber, V. \& Svejgaard, A. (1989) The HIV-induced immunodeficiency: Relatively preserved PHA as opposed to decreased (1989) The HIV-induced immunodeficiency: Relatively preserved PHA as opposed to decreased PWM responses may be due to possibly preserved response via CD2/PHA pathway. J. Immunol. 142, 1874-1880.

11. Wachter, H., Fuchs, D., Hausen, A., Huber, C., Knosp, O., Reibnegger \& G., Spira, T. (1983) Elevated urinary neopterin levels in patients with AIDS. Hoppe-Seyler's Z. Physiol. Chem. 364, 1345-1346.

12. Fuchs, D., Reibnegger, G., Reissigl, H., Schonitzer, D., Spira, T. \& Wachter, H. (1984) Urinary neopterin in the diagnosis of acquired immune deficiency syndrome. Eur. J. Clin. Microbiol. 3, 70-71.

13. Jenkins, M. K. (1992) The role of cell division in the induction of clonal angergy. Immunol. Today $13,69-73$.
14. Schroff, R. W., Gottlieb, M. S., Prince, H. E., Chai, L. L. \& Fahey, J. L. (1983) Immunological studies of homosexual men with immunodeficiency and Kaposi's sarcoma. Clin. Immunol. Immunopathol. 27, 300-314.

15. Martinez-Maza, O., Crabb, E., Mitsuyasu, R. T., Fahey, J. L. \& Giorgi, J. V. (1987) Infection with HIV is associated with an in vivo increase in B lymphocyte activation and immaturity. J. Immunol. 138, 3702-3724.

16. Fahey, J. L., Taylor, J., Detels, R., Hofmann, B., Melmed, R., Nishanian, P. \& Georgi, J. V. (1990) The prognostic value of cellular and serologic markers in infection with human immunodeficiency virus type 1 . N. Eng. J. Med. $322,166-172$.

17. Melmed, R. N., Taylor, J. M. G., Detels, R., Bozorgmehri, M. \& Fahey, J. L. (1989) Serum neopterin changes in HIVinfected subjects: indicator of significant pathology, CD4 $\mathrm{T}$ cell change and the development of AIDS. J. AIDS 2, $70-76$.

18. Hofmann, B., Wang, Y., Cumberland, W. G., Detels, R., Bozorgmehri, M. \& Fahey, J. L. (1990) Serum beta 2 -microglobulin level increases in HIV infection: Relation to seroconversion, CD4 $\mathrm{T}$ cell fall and prognosis. AIDS 4, 207-214.

19. Hofmann, B., Nishanian, P., Fahey, J. L., Esmail, E., Jackson, A. L., Detels, R. \& Cumberland, W. (1991) Serum increases and lymphoid cell surface losses of IL-2 receptor CD25 in HIV infection: Distinctive parameters of HIVinduced change. J. Clin. Immunol. Immunopathol. 61 , $212-224$.

20. Nishanian, P., Hofmann, B., Wang, Y., Jackson, A. L., Detels, R. \& Fahey, J. L. (1991) Serum soluble CD8 molecule is a marker of immune activation in HIV disease. AIDS 5, 805-812.

21. Prince, H. E., Kleinman, S., Czaplicki, C., John, J. \& Williams, A. E. (1990) Interrelationships between serological markers of immune activation and $\mathrm{T}$ lymphocyte subsets in HIV infection. J. AIDS 3, 525-530.

22. Fuchs, D., Hausen, A., Reibnegger, G., Werner, E. R., Werner-Flemayer, G., Dierich, M. P. \& Wachter, H. (1989) Interferon-gamma concentrations are increased in sera from individuals infected with human immunodeficiency virus type 1. J. AIDS 2, 158-162.

23. Breen, E. C., Rezai, A. R., Nakajima, K., Beall, G. N., Nitsuyasu, R. T., Hirano, T., Kishimoto, T. \& MartinezMaza, O. (1990) Infection with HIV is associated with elevated IL-6 levels and production. J. Immunol. 144, 480484.

24. Fuchs, D., Albert, J., Åsjo, B., Fenyo, E. M., Reibnegger, G. \& Wachter, H. (1989) Associations between serum neopterin concentrations and in vitro replicative capacity of HIV-1 isolates. J. Infect. Diseases 160, 724 725 .

25. Fuchs, D., Shearer, G. M., Boswell, R. N., Clerici, M., Reibnegger, G., Werner, E. R., Zajac, R: A. \& Wachter, H. (1990) Increased serum neopterin in patients with HIV-1 infection is correlated with reduced in vitro interleukin-2 production. Clin. Exp. Immunol. 80, 44-48.

26. Gaines, H., von Sydow, M. A. E., von Stedingk, L. V., Biberfeld, G., Bottiger, B., Hansson, L. O., Lundbergh, P., Sonnerborg, A. B., Wasserman, J. \& Strannegåard, O. O. (1990) Immunological changes in primary HIV-1 infection. AIDS 4, 995-999. 
27. Popov, J., McGraw, T., Hofmann, B., Vowels, B., Shum, A., Nishanian, P. \& Fahey, J. L. (1992) Immune activation in acute and ongoing SIV infection. J. AIDS 5, 391-399.

28. Hutterer, J., Fuchs, D., Eder, G., Knapp, W., Koller, U., Reibnegger, G., Werner, E. R., Wachter, H., Stingl, G. \& Wolff, K. (1987) Neopterin as discriminating and prognostic parameter in healthy homosexuals, ARC and AIDS patients. Wien. Klin. Wochenschr. 99, 531-535.

29. Fuchs, D., Kramer, A., Reibnegger, G., Werner, E. R., Dierich, M. P., Goedert, J. J. \& Wachter, H. (1991) Neopterin and beta- 2 microglobulin as prognostic indices in human immunodeficiency virus type 1 infection. Infection 19. $\mathrm{S} 98-102$.

30. Osmond, D. H., Shiboski, S., Bacchetti, P., Winger, E. E. \& Moss, A. R. (1991) Immune activation markers and AIDS prognosis. AIDS 5, 505-511.

31. Fuchs, D., Jager, H., Popescu, M., Reibnegger, G., Werner, E. R., Dierich, M. P., Kaboth, W., Tilz, G. P. \& Wachter, H. (1990) Immune activation markers to predict AIDS and survival in HIV-1 seropositives. Immunol. Letters 26 , 75-80.

32. Fuchs, D., Spira, T. J., Hausen, A., Reibnegger, G., Werner, E. R., Felmayer, G. W. \& Wachter, H. (1989) Neopterin as a predictive marker for disease progression in human immunodeficiency virus type 1 infection. Clin. Chem. 35, 1746-1749.

33. Zangerle, R., Fuchs, D., Reibnegger, G., Fritsch, P. \& Wachter, H. (1991) Markers for disease progression in intravenous drug users infected with HIV-1. AIDS 5, 985991.

34. Fuchs, D., Reibnegger, G., Werner, E. R., Vinazzer, H. \& Wachter, H. (1991) Low haemoglobin in haemophilia children is associated with chronic immune activation. Acta Haematol. 85, 62-65.

35. Ujhelyi, E., Fuchs, D., Krall, G., Zimonyi, I., Berkessy, S., Bujdoso, S., Paloczi, K., Mihalik, R., Fust, G. \& Wachter, H. (1990) Age dependency of the progression of HIV disease in haemophiliacs; predictive value of $\mathrm{T}$ cell subjects and neopterin measurements. Immunol. Letters 26,67-73.

36. Cuthbert, R. J. G., Ludlam, C. A., Tucker, J., Steel, C. M., Beatson, D., Rebus, S. \& Peutherer, J. F. (1990) Five year prospective study of HIV infection in the Edinburgh haemophiliac cohort. Br. Med. J. 301, 956-961.

37. Fuchs, D., Unterweger, B., Hausen, A., Reibnegger, G., Werner, E. R., Hengster, P., Hartmann, H., Dierich, M. P., Wachter, H., Blattner, W. A. \& Weiss, S. H. (1988) AntiHIV-1 antibodies, anti-HTLV-1 antibodies and neopterin levels in parenteral drug addicts in the Austrian Tyrol. J. AIDS 1, 65-66.

38. Hengster, P., Schmutzhard, E., Fuchs, U., Hofbauer, J., Wachter, H. \& Dierich, M. P. (1991) Evaluation on HIV serology and immune-stimulation on patients in Tanzania. International J. of STD and AIDS 2, 180-184.

39. Pepin, J., Morgan, G., Dunn, D., Gevao, S., Mendy, M., Gaye, I., Scollen, N., Tedder, R. \& Whittle, H. (1991) HIV2 -induced immunosuppression among asymptomatic West African prostitutes: Evidence that HIV-2 is pathogenic but less so than HIV-1. AIDS 5, 1165-1172.
40. Schmutzhard, E., Fuchs, D., Hengster, P., Hausen, A., Pohl, P.; Rainer, J., Reibnegger, G., Libyempansha, U. \& Werner, E. R. (1989) Retroviral infections (HIV-1, HIV-2 and HTLV-1) in rural northwestern Tanzania. Am. J. Epidemiol. 130, 309-318.

41. Charisson, R. E., Taylor, E., Margolick, J. B., Munoz, A. Solomon, L., Cohn, S., Nelson, R. E. \& Vlahov, U. (1992) Immune serum markers and CD4 cell counts in HIVinfected intravenous drug users. J. AIDS 5, 456-460.

42. Monforte, A. dÁ., Ravizza, M., Muggiasca, M. L., Novati, R., Musicco, M., Zuccotti, G. V., Cavalli, G., Principi, N., Conti, M., Pardi, G. \& Lazzarin, A. (1991) Maternal predictors of HIV vertical transmission. Eur. J. Obstetr. Gynecol. Reprod. Biol. 42, 131-136.

43. Chan, M. M., Campos, J. M., Josephs, S. \& Rifai, N. (1990) Beta-2 microglobulin and neopterin: Predictive markers for human immunodeficiency virus type 1 infection in children. J. Clin. Microbiol. 28, 2215-2219.

44. Rautonen, J., Martin, N. L., Rautonen, N. \& Wara, D. W. (1991) Neopterin in diagnosis of HIV in infants. J. Clin. Microbiol. 29, 850-851.

45. Ellaurie, M., Calvelli, T. \& Rubinstein, A. (1992) Neopterin concentrations in pediatric human immunodeficiency virus infection as predictor of disease activity. Pediatr. Infect. Dis. J. 11, 286-289.

46. Sonnerborg, A. B., von Stedingk, L. V., Hansson, L. O. \& Strannegard, O. O. (1989) Elevated neopterin and beta-s microglobulin levels in blood and cerebrospinal fluid occur early in HIV-1 infection. AIDS 3, 277-283.

47. Peter, J. B., McKeown, K. L., Barka, N. E., Tourtellotte, W. W., Singer, E. J. \& Syndulko, K. (1991) Neopterin and beta-2 microglobulin and the assessment of intra-bloodbrain-barrier synthesis of HIV-specific and total IgG. J. Clin. Lab. Anal. 5, 317-320.

48. Griffin, D. E., McArthur, J. C. \& Cornblath, D. R. (1991) Neopterin and interferon-gamma in serum and cerebrospinal fluid of patients with HIV-associated neurologic disease. Neurology 41, 69-74.

49. Hutterer, J., Armbruster, C., Wallner, G., Fuchs, D., Vetter, N. \& Wachter, H. (1992) Early changes of neopterin concentrations during treatment of human immunodeficiency virus infection with zidovudine. J. Infect. Diseases 165 , $783-784$.

50. Bass, H., Hardy, W. D., Mitsuyasu, R. T., Taylor, J. M. G., Wang, Y. X., Fischl, M. A., Spector, S. A., Richman, D. D. \& Fahey, J. L. (1992) The effect of zidovudine treatment on serum neopterin and beta ${ }_{2}$-microglobulin levels in mildly symptomatic, HIV type 1 seropositive individuals. J. AIDS 5, 215-221.

51. Jacobsen, M. A., Bacchetti, P., Kolokathis, A., Chaisson, R. E., Szabo, S., Polsky, B., Valainis, G. T., Midlvan, D., Abrams, D., Wilber, J., Winger, E., Sacks, H. S., Hendricksen, C. \& Moss, A. (1991) Surrogate markers for survival in patients with AIDS and AIDS related complex treated with zidovudine. Brit. Med. J. 302, 73-78.

\author{
Dr. Bo Hofmann \\ Department of Infectious Diseases \\ Hvidovre Hospital \\ Municipality of Copenhagen University \\ Kettegaards alle 30 \\ DK-2650 \\ Denmark
}


